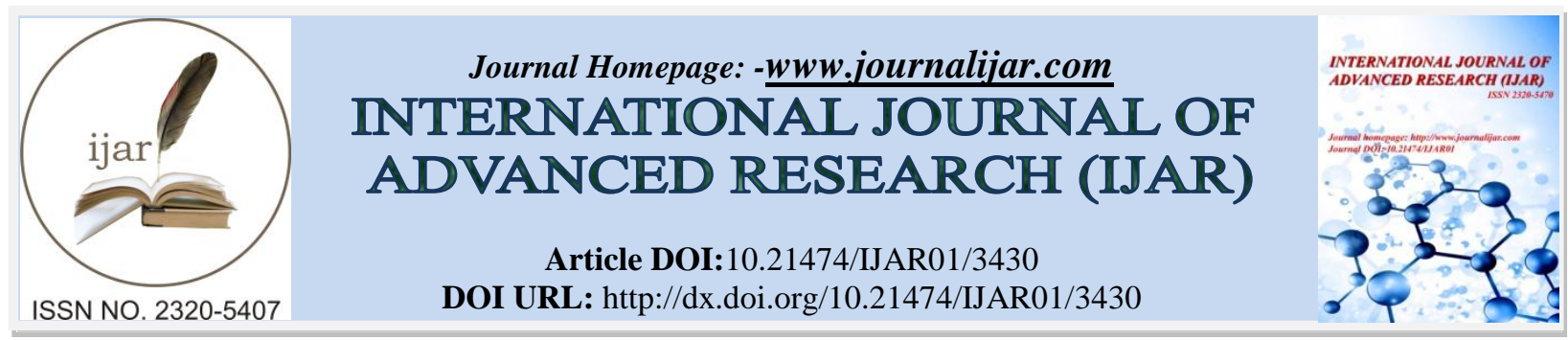

RESEARCH ARTICLE

\title{
COMPARISON OF EFFICACY OF INFUSIONS OF DEXMEDETOMIDINE VERSUS BUTORPHANOL AS SEDATIVE \& ANALGESIC IN SHORT GENERAL ANAESTHESIA IN DAY CARE GYNAECOLOGICAL SURGERIES.
}

\author{
Dr. Anuja Agrawal, Dr. Jitender Chauhan and Dr. Hetal Parikh.
}

\section{Manuscript Info}

Manuscript History

Received: 25 December 2016

Final Accepted: 16 January 2017

Published: February 2017

Key words:-

Dexmedetomidine, butorphanol, day care, analgesia, Ramsay Sedation Score.

\section{Abstract}

Background And Goals: Development of selective alpha 2 adrenoceptor agonists may provide a new concept for the administration of periopertive anaesthesia \& analgesia in day care surgeries.Goal of this study was to compare Inj.Dexmedetomidine\&Inj.Butorphanol with respect to time required for onset \& offset of sedation, quality of intraoperative as well as postoperative analgesia $\&$ the time required for post-operative recovery.

Methods: After obtaining permission from Institutional Ethical Committee (IEC), study was conducted in 40 patients of ASA I and \| divided into 2 groups A \& B by computer generated random number table. Patients, in group A received injDexmedetomidine $1 \mathrm{mcg} / \mathrm{kg}$ i.v and group B received inj.Butorphanol $10 \mathrm{mcg} / \mathrm{kg}$ i.v, in infusion over 10 minutes prior to induction. Induction was done with injPropofol i.v $2 \mathrm{mg} / \mathrm{kg} \&$ maintained with $33 \% \quad \mathrm{O} 2,66 \% \mathrm{~N} 2 \mathrm{O} \& 0.6-0.8 \%$ of isoflurane with patient breathing spontaneously. Throughout the surgery the sedation and analgesia was maintained with injDexmedetomidine $0.7 \mathrm{microgram} / \mathrm{kg} / \mathrm{hr}$ infusion in group A and with injButorphanol $2 \mathrm{microgram} / \mathrm{kg} / \mathrm{hr}$ in group B. Patients were evaluated in postoperative recovery room with help of Visual Analogue Scale (VAS) for pain, Ramsay Sedation Score \& Standard Aldrete Score for recovery.

Results: Demographically, the two groups were similar. Requirement of inhalationalanaesthetic agents was significantly reduced in the group A $(p<0.05)$.VAS was significantly less $(2.75 \bigcirc 0.44)$ in the group B after 90 min and earlier rescue analgesia was given in group A ( p < $0.05)$. Eye opening was earlier (45.5 23.61) in group A and was highly significant $(\mathrm{p}<0.001)$. Postop recovery was significantly improved $(9.8 \diamond 0.41)$ with dexmeditomidinegroup. Conclusion: Dexmedetomidine produces better sedation and analgesia without significant adverse effects and can be used as sole sedative and analgesic for day care surgery patients with better recovery.

Copy Right, IJAR, 2017,. All rights reserved. 


\section{Introduction:-}

Pain is "an unpleasant sensory and emotional experience associated with actual or potential tissue damage, or described in terms of such damage." ${ }^{[1]}$

Dexmeditomidine is the dextrorotatory s-enantiomer of meditomidine. It is a $\alpha-2$ agonist. Use of $\alpha-2$ adrenoceptor agonist is not new, it dates back to 1960's but it was approved in December 1999, as the most recent agent in this group and was introduced into clinical practice as a short-term sedative ( $<24$ hours). The development of new, more selective $\alpha_{2}$-adrenoceptor agonists with improved side effect profiles may provide a new concept for the administration of perioperative anesthesia and analgesia.

Dexmeditomidine, mechanism of action is unique and differs from those of currently used sedative agents, including clonidine. By binding to the presynaptic alpha-2 adrenoceptor, it inhibits the release of norepinephrine, therefore, terminate the propagation of pain signals. Activation of the postsynaptic alpha-2 decrease sympathetic tone, with attenuation of the neuroendocrine and hemodynamic responses to anesthesia and surgery; reduce anesthetic and opioid requirements; and cause sedation and analgesia. They allow psychometric function to be preserved while letting the patient rest comfortably.

Butorphanol tartrate, (-) - 17 - (Cyclobutyl-methyl) morphinan-3, 14 - diol D- (-) -tartrate (1:1) (salt), is a synthetic intermediate acting opioid, agonist-antagonist of phenanthrene series. Butorphanol tartrate exhibits partial agonistantagonist activity at $\mu$ opioid receptor and agonist activity at the $\kappa$ opioid receptor. It is five times more potent than morphine. An analgesic dose of butorphanol tartrate given by i.m, i.v or epidural route often produces marked sedation $^{[2]}$. Butorphanol tartrate is a time tested analgesic used commonly in anaesthetic practice.

Dexmeditomidine has been recently added to the armamentarium of anaesthesiologists for intra-operative and postoperative analgesia $^{[3]}$. In this study we have compared it with butorphanol tartrate when used in providing intraoperative and post-operative analgesia.

\section{Aims and Objectives:-}

1. To compare Dexmeditomidine with Butraphanol in short general anaesthesia- day care surgeries.

2. To see whether Dexmeditomidine and Butraphanol reduce the induction dose of propofol and volatile inhalationalanaesthetics.

3. To compare the untoward effects of Dexmeditomidine and Butraphanol.

4. To compare the efficacy of Dexmeditomidine achieving intraoperative and postoperative analgesia with that produced by using Butraphanol.

\section{Materials \& Method:-}

- Prior permission of institutional ethical committee was obtained to conduct the study.

- The study was conducted in 40 patients. In group A patients received Dexmedetomidine $(\mathrm{n}=20)$ \& in group B patients received Butorphanol $(\mathrm{n}=20)$.

- All patients were subjected to thorough pre-anesthetic evaluation and relevant laboratory investigation.

\section{Inclusion Criteria:-}

1. ASA grade I or II.

2. Age 18-60 years.

3. Availability of informed consent.

4. Patients undergoing elective short gynaecological procedures under short general anaesthesia.

5. Hemodynamically stable patients with all routine investigations within normal limits.

\section{Exclusion criteria:-}

1. Patients unwilling or hesitant to undergo the procedure under prescribed anaesthesia.

2. Patients with known hypersensitivity to opioids.

3. Patients addicted to opioids.

4. Patients with chronic obstructive pulmonary disease, bronchial asthma and or respiratory insufficiency.

5. Patients with head trauma and raised intracranial pressure due to any cause.

6. Patients suffering from psychiatric illnesses. 


\section{Emergency surgeries}

\section{Method of randomisation:-}

A statistician was consulted and with the help of computer generated table the randomization was done, adequacy of sample size and power of test was confirmed and then 40 patients were divided into 2 equal groups of 20 patients each ie. Group A and group B.

- Group A: Patients were given Inj.Dexmedetomidine $1 \mathrm{mcg} / \mathrm{kg}$ body weight as loading dose and maintained on $0.7 \mathrm{mcg} / \mathrm{kg}$ body weight.

- Group B : Patients were given Inj.butraphanol10 $\mathrm{mcg} / \mathrm{kg}$ body weight and maintained on $2 \mathrm{mcg} / \mathrm{kg}$ body weight

\section{Methodology:-}

Anaesthetic plan was discussed and explained to all the patients a day prior to surgery. Patients were asked for any previous history of allergy to any anaesthetic given before or any kind of medication.

All patients were kept fasting overnight prior to scheduled day of operation.

In operation theatre, pre-operative vitals i.e. Pulse rate, BP, oxygen saturation were recorded. 20 gauge i.v cannula was placed in situ. All patients received inj.glycopyrolate $0.004 \mathrm{mg}$ per $\mathrm{kg}$ body weight and injondansteron $0.1 \mathrm{~g}$ per $\mathrm{kg}$ body weight intravenously and inj.dexmedetomidine 1 microgram $/ \mathrm{kg}$ body weight intravenously in infusion pump over 10 minutes prior to induction of GA in group A \&inj.Butraphanol10 $\mathrm{mcg} / \mathrm{kg}$ in infusion pump over 10 minutes body weight intravenously prior to induction of GA.

After medication patients in both the groups were analysed for sedation using Ramsay sedation scale $\&$ anxiety prior to induction.

\begin{tabular}{|c|c|}
\hline LEVEL OF ACTIITY & POINTS \\
\hline Patient anxious, agitated or restless & 1 \\
\hline Patient cooperative, orientated and tranquil & 2 \\
\hline Patient responding only to verbal commands & 3 \\
\hline $\begin{array}{l}\text { Patient with brisk response to light glabella tap or loud } \\
\text { audilory stimulus }\end{array}$ & 4 \\
\hline $\begin{array}{l}\text { Patient with sluggish response to light glabella tap or loud } \\
\text { auditory simulus }\end{array}$ & 5 \\
\hline $\begin{array}{l}\text { Patient with no response to light glabella tap or loud } \\
\text { auditory stimulus }\end{array}$ & 6 \\
\hline
\end{tabular}

Source: Arq. Bras. Cardiol. vol.93 no.6 São Paulo Dec. 2009.

All the patients of group A were maintained on $0.7 \mathrm{mcg} / \mathrm{kg}$ dexmeditomidine infusion and all the patients of group B were maintained on $2 \mathrm{mcg} / \mathrm{kg}$ butarphanol infusion. Infusions were stopped 5 minutes prior to end of surgery.

Following preoxygenation induction of GA was done with inj. propofol $2 \mathrm{mg} / \mathrm{kg}$ body wt. After the loss of eyelash reflex / patient in apnea patients were ventilated via face mask till the patient regains the spontaneous ventilation. Anaesthesia was maintained with $33 \%$ oxygen, $66 \%$ nitrous oxide and isoflurane $(0.5 \%$ to $0.8 \%)$, with the patient breathing spontaneously. In the recovery room patient were followed up for vitals, for pain using visual analog scale $\&$ standard Aldrete score ${ }^{[14]}$ for recovery. 
Table 2:- Vas.

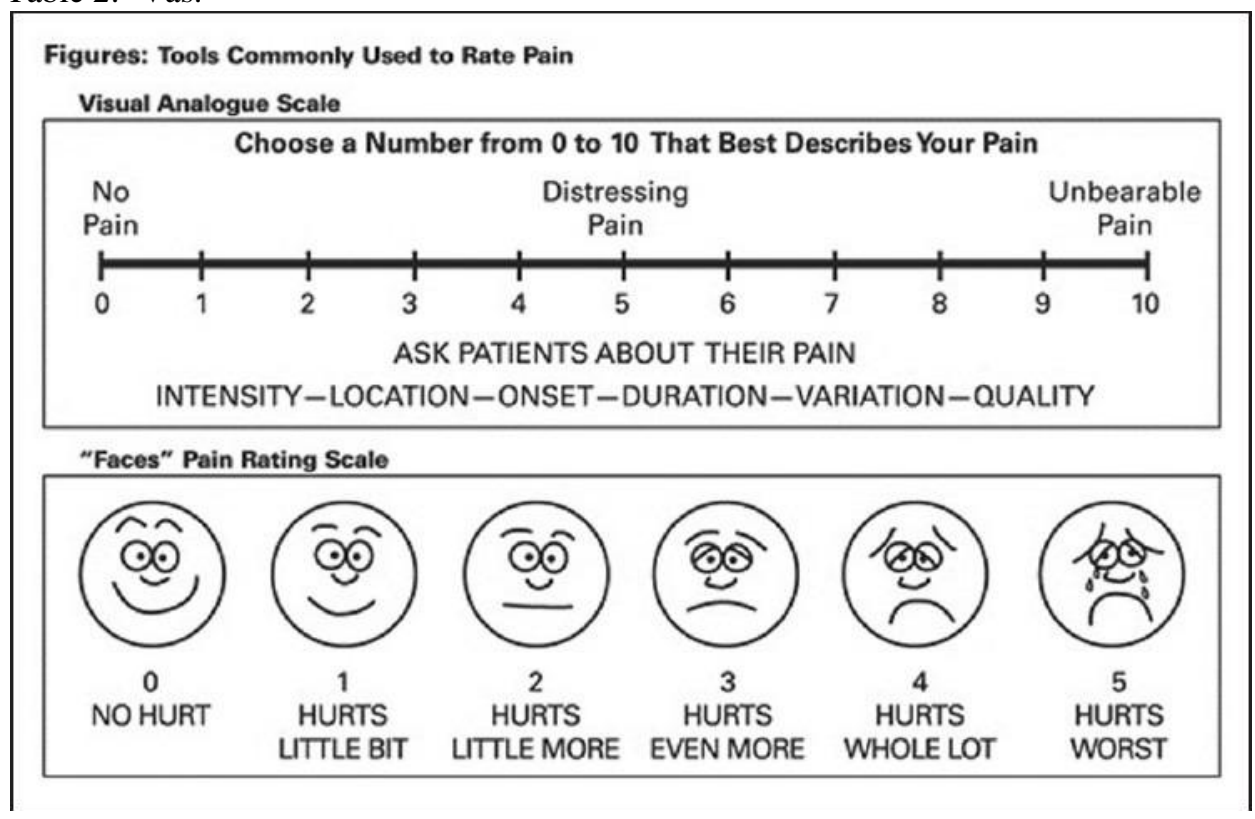

Table 3:-Standard Aldrete score.

\begin{tabular}{ll}
\hline Criteria & Points \\
\hline Vital signs & 2 \\
Within 20\% of preoperative baseline & 1 \\
Within 20 40\% of preoperative baseline & 0 \\
$\quad$ 40\% of preoperative baseline & \\
Activity level & 2 \\
$\quad$ Steady gait, no dizziness, at preoperative level & 1 \\
Requires assistance & 0 \\
Unable to ambulate & \\
Nausea and vomiting & 2 \\
Minimal, treated with oral medication & 1 \\
Moderate, treated with parenteral medication & 0 \\
Continues after repeated medication & \\
Pain: minimal or none, acceptable to patient, & \\
$\quad$ controlled with oral medication & 2 \\
Yes & 1 \\
No & \\
Surgical bleeding & 2 \\
Minimal: no dressing change required & 1 \\
Moderate: up to two dressing changes & 0 \\
Severe: three or more dressing changes
\end{tabular}

Source: Rev. bras. ter. intensiva vol.21 no.2 São Paulo Apr./June 2009 
Along with this, vitals were monitored. (Pulse, $\mathrm{BP}, \mathrm{SPO}_{2}$ and $\mathrm{RR}$ ). The patient were followed up until the VAS was more than or equal to 5 .

Then the rescue analgesia will be given if required.

The time will be noted and patient will be released from the study.

Results in both groups will be tabulated and compared to draw the conclusion.

\section{Parameters Recorded:-}

1. Pre operative vitals

2. Base line vitals before premedication.

3. Vitals before induction.

4. Intra operative events (average).

5. Post operative vitals.

6. Duration of surgery

7. V.A.S score :

* $\mathrm{T}_{0}$ - at the time of premedication: drugs to be given.

* $\mathrm{T}_{1}$ - when patient wakes up/responds to verbal stimuli

* $\mathrm{T}_{2-}$ - when patient starts complaining of pain with V.A.S > or equal to 5 (rescue analgesia to be given)

* $\mathrm{T}_{1}-\mathrm{T}_{2}=$ total duration of action

8. Ramsay sedation score.

9. Standard aldrete score for recovery.

\section{Results:-}

There was no significant difference in pulse rate. There was significant fall in systolic $(\mathrm{z}=2.55)$ and diastolic $(\mathrm{z}=$ 2.04) blood pressure in dexmedetomidine group after induction. $(\mathrm{p}<0.05)$. Requirement of inhalationalanaesthetic agents was significantly reduced in the dexmedetomidine group $(\mathrm{p}<0.05)$ as compared to the butorphanol group (graph 1). VAS was significantly less $(2.750 .44)$ in the butorphanol group after 90 min and earlier rescue analgesia was given in dexmedetomidine group ( $\mathrm{p}<0.05)$ (graph 2). Sedation score in both the groups was similar as assessed by Ramsay sedation score. Eye opening was earlier (45.5 23.61) in dexmedetomidine group as compared to the butorphanol group and was highly significant as p $<0.001$ (graph 3). Recovery was significantly improved $(9.8 \geqslant 0.41)$ with dexmedetomidine group than butorphanol group and its $\mathrm{p}<0.001$ as assessed by Standard Aldrete Score. (graph 4)

\section{Graph 1:-}

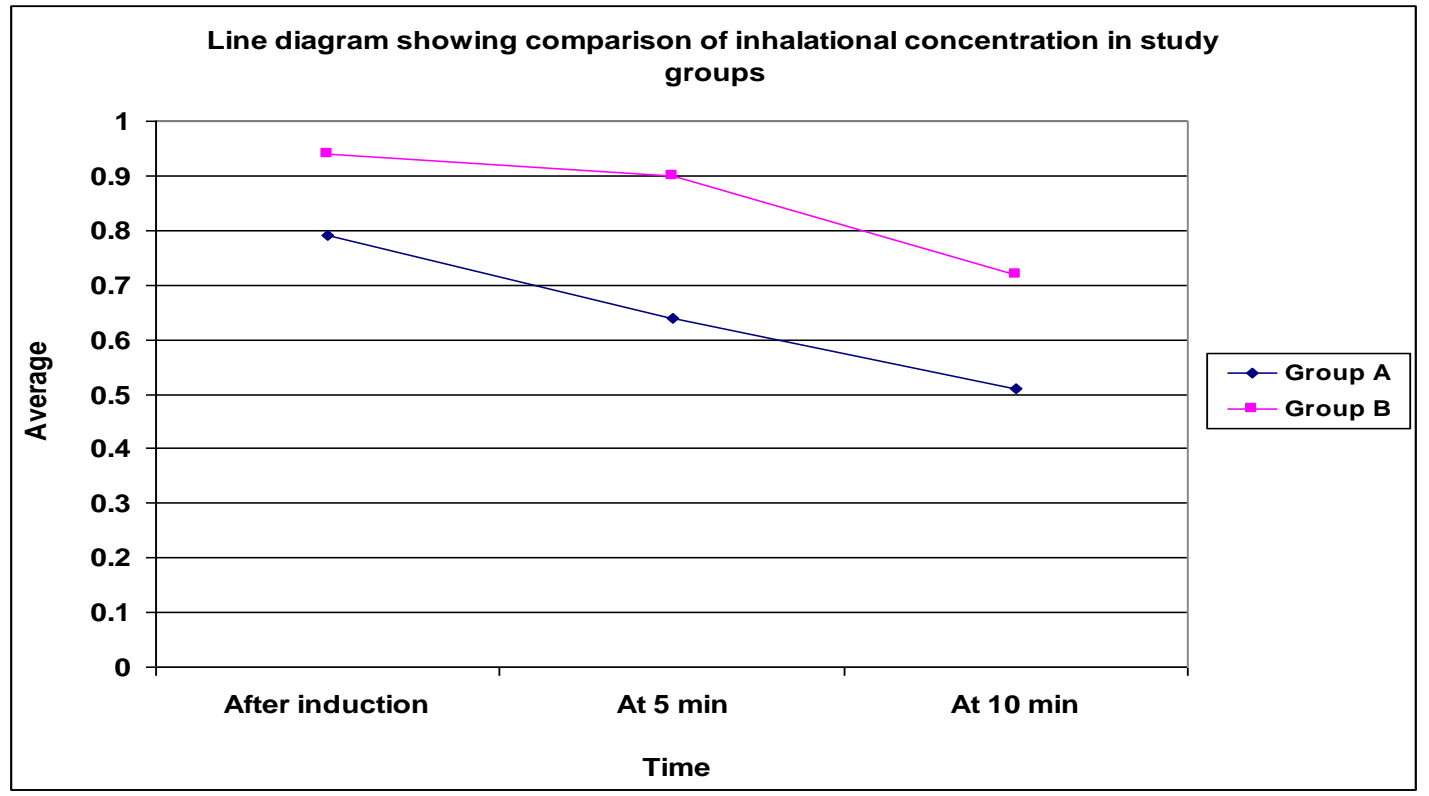


Graph 2:-

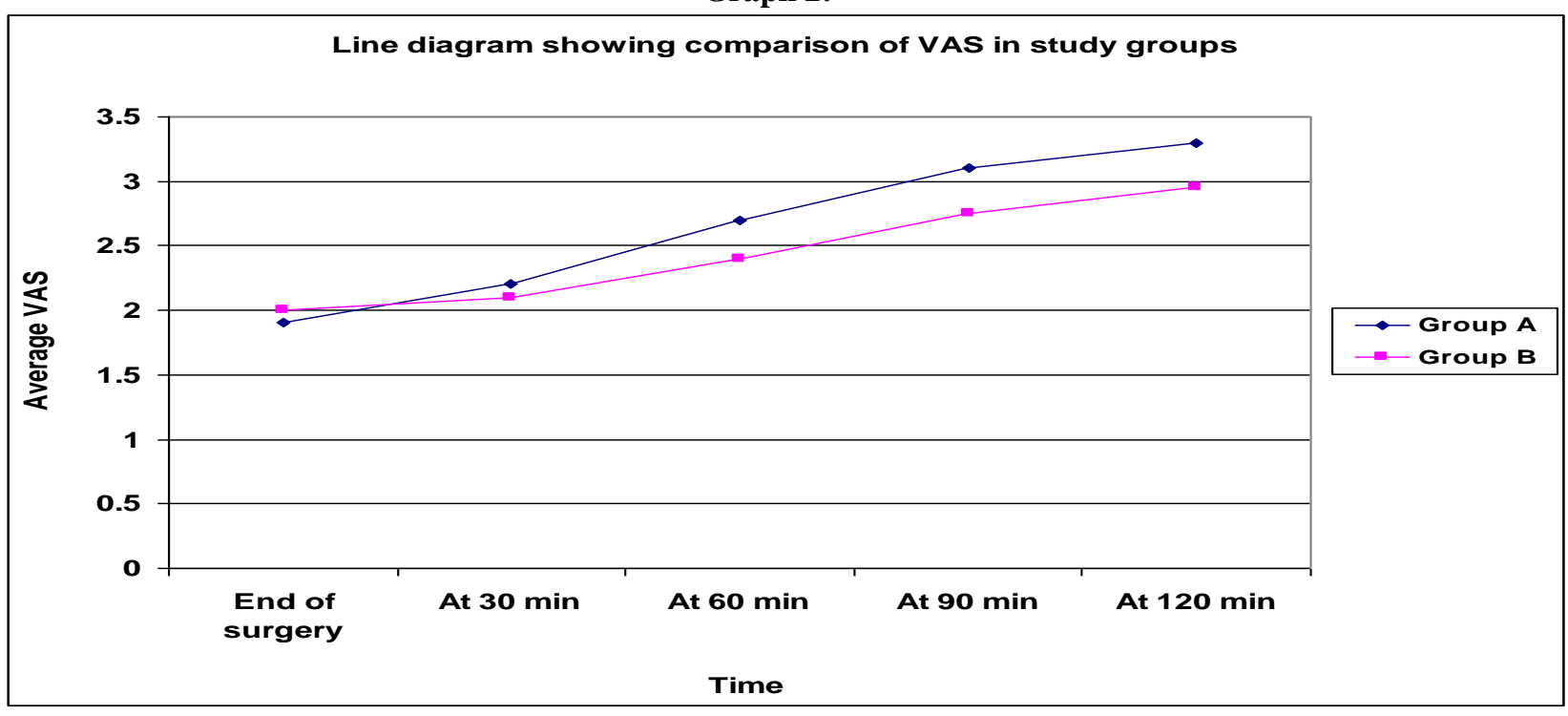

Graph 3:-

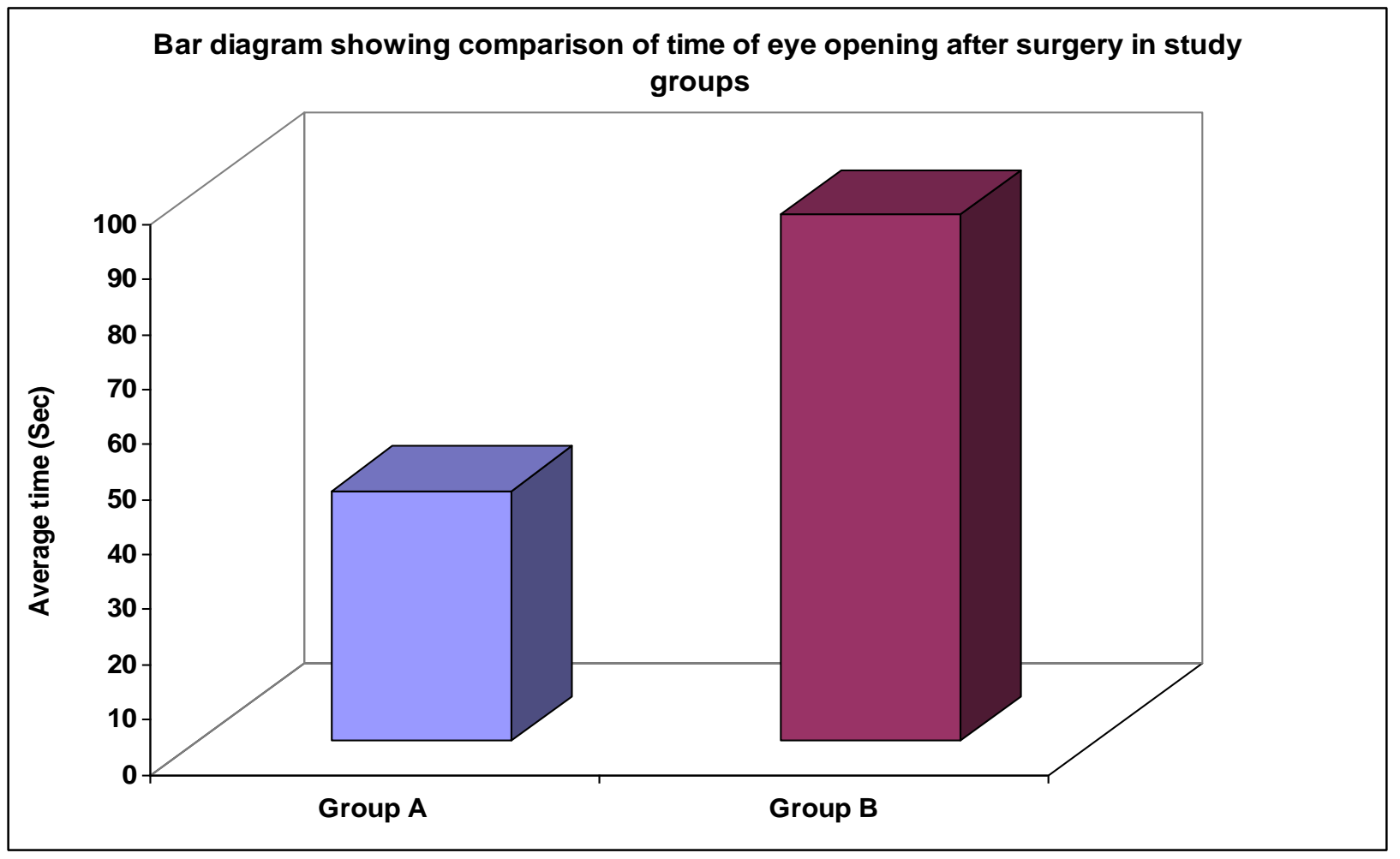




\section{Graph 4:-}

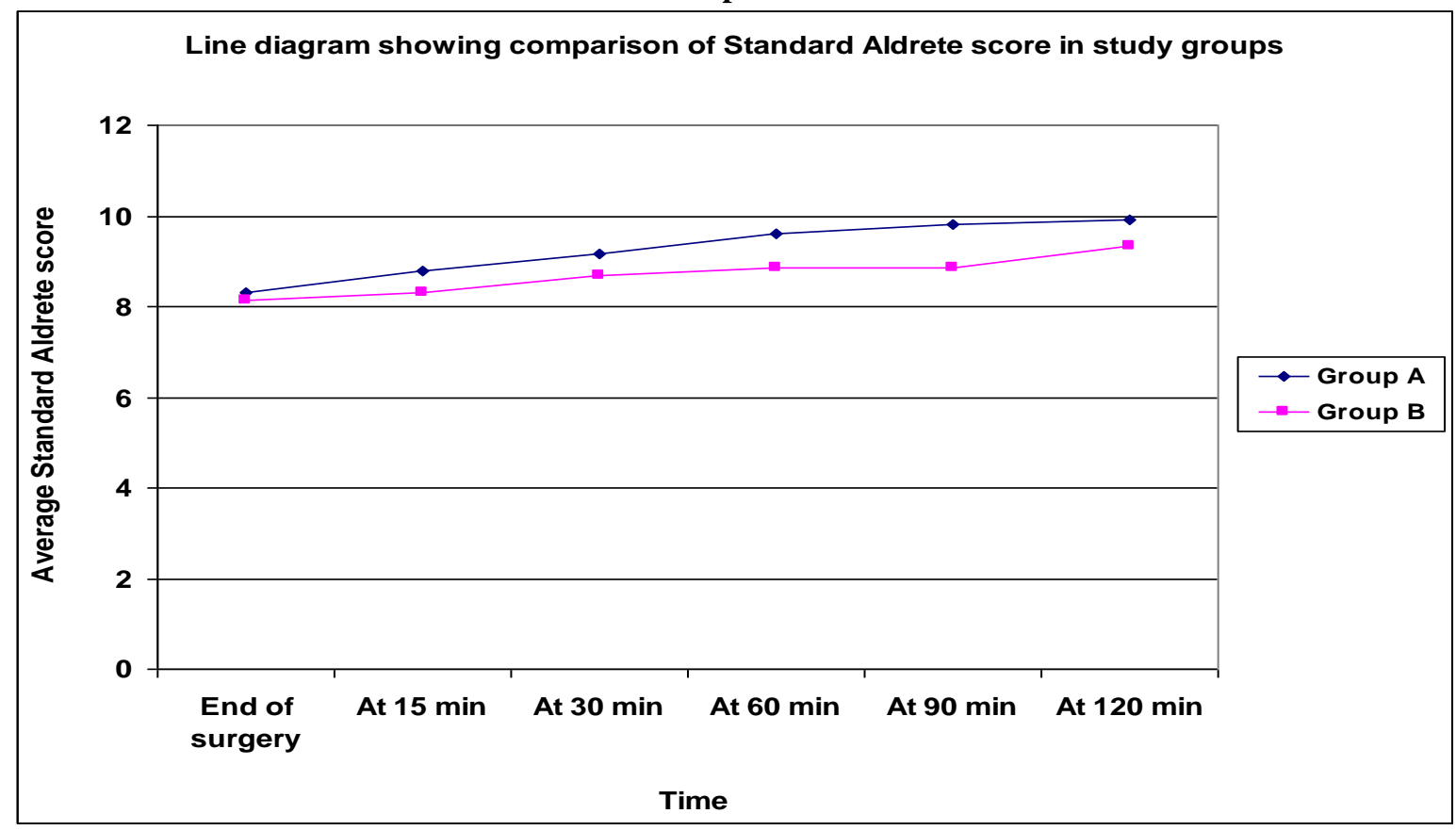

\section{Discussion:-}

In the modern day hospitals, there is an established principle of ambulating the surgical patient as early as possible. Day care surgery has been defined by the Royal College of Surgeons as when the surgical day case patient is admitted for investigation or operation on a planned non-resident basis and who requires facilities for recovery. This definition excludes upper and lower GI endoscopies, outpatient procedures such as flexible cystoscopy, and minor superficial surgery under local anaesthetic, none of which require full day care facilities for recovery. It is important to mention that day care surgery is different from out-patient surgery in that the patients of day care surgery need some degree of post-operative observation for a few hours. All day care surgical patients essentially come early in the morning and after the surgery is over and the post-operative observation is uneventful, the patient is discharged home the same day.

The reduction in cost to both the patient and community, coupled with the advantages of Day Surgery for both patients and their relatives, have served to increase the demand for Day Surgery. The use of a Day surgery facility reduces the number of in-patient beds required. Shortened hospital stays and earlier mobilisation also reduces the risk of hospital-acquired infections and venous thromboembolism (VTE). The bulk of these patients come from specialties of ophthalmology and ENT, followed by Gynaecology and General Surgery. The other super-specialties only contribute a very small fraction ${ }^{4}$.

In last few years, a great enthusiasm has been shown toward the use of $\alpha 2$ agonists in anaesthesia practice because it has been found to decrease serum catecholamine levels by upto $90 \%,{ }^{5}$ to blunt the haemodynamic response to laryngoscopy, tracheal intubation, pneumoperitoneum and extubation ${ }^{6}$, to provide sedation without respiratory depression and to decrease post-operative analgesic requirements ${ }^{7}$.

Whereas butorphanol is used as a pre-anesthesia adjunct, narcotic analgesic for the relief of moderate to severe migraine, postoperative, or obstetric pain. Early studies suggested that butorphanol did not produce compete respiratory depressant effects and a 'plateau or ceiling effect' was observed ${ }^{8}$.

In 2003, Ard et al and Nelson et al suggested that Dexmedetomidine provides sedation, analgesia, and anxiolysis with minimal effect on respiratory function during the awake craniotomy similar to sedation during natural sleep.

In 2009, Wang F et al studyfound in a study that the butorphanol combined with intravenous morphine PCA in patients undergoing abdominal hysterectomy shows effective analgesia with sedation and fewer side effects. This 
study also demonstrated that the butorphanol group had analgesia superior to the physiological saline control. The study found that there were no differences between urinary catheterization of more than $24 \mathrm{~h}$, first time out of bed and time to discharge to home.

We choose butorphanol as drug of comparison with dexmedetomidine because the analgesic activity is 4-7 times that of morphine, 15-30 times that of pentazocine and has fewer side effects than other opioids and all of them can be reversed by naloxone. The safe dose of butorphanol that can be given intravenously is $20-40 \mu \mathrm{g} / \mathrm{kg}^{9}$. We have used $10 \mu \mathrm{g} / \mathrm{kg}$ of butorphanol in our study. The duration of analgesia after intravenous injection of 1 or $2 \mathrm{mg}$ of Butorphanol lasts for 3-5 hours.

\section{Conclusion:-}

Our study demonstrated that dexmedetomidine produces better sedation and analgesia without significant adverse effects compared to butorphanol. It can be used as sole sedative and analgesic for day care surgery patients. Patients also show better and faster recovery on usage of dexmedetomidine.

\section{Bibliography:-}

1. Association for the Study of Pain, Subcommittee on Taxonomy: Classification of chronic pain: Descriptions of chronic pain syndromes and definitions of pain terms. Pain 1986; (suppl 3):S1-225.

2. Caruso FS, Pirio AW, Madisso H, Smyth RD, Pachter IJ : Butorphanol, pharmacological and biochemical properties of drug substances. Vol 2. Edited by Goldbrg ME. Washington, American pharmaceutical association, academy of pharmaceutical sciences, 1979, PP 1957.

3. Aho M, Erkola O, Kallio A, Scheinin H, Korttila K. Dexmedetomidine infusion for maintenance of anesthesia in patients undergoing abdominal hysterectomy. AnesthAnalg 75:940-6, 1992.

4. Naresh RT. Ambulatory Surgery: The Indian Perspective. Cir. May. Amb. 2005; Vol $10 \quad$ (supl): 19-20.

5. Bloor BC, Ward DS, Belleville JP, Maze M. Effects of intravenous dexmedetomidine in humans. II. Hemodynamic changes. Anesthesiology 1992;77:1134-42.

6. Isik B, Arslan M, Özsoylar O, Akçabay M. The effects of $\alpha 2$-adrenergic receptor agonist dexmedetomidine on hemodynamic response in direct laryngoscopy. Open Otorhinolaryngol J 2007;1:5-11.

7. Gurbet A, Basagan-Mogol E, Turker G, Ugun F, Kaya FN, Ozcan B. Intraoperative infusion of dexmedetomidine reduces perioperative analgesic requirements. Can J Anaesth2006;53:646-52.

8. Kallos T and Caruso FS (1979) Respiratory effects of butorphanol and pethidine. Anaesthesia 34:633-637.

9. WHO's Certified [Internet]. $34^{\text {th }}$ ECDD 2006/4.1 Critical review of BUTORPHANOL. Available from: http://www.who.int/medicines/areas/quality_safety/4.1ButhorphanolCritReview.pdf [Last cited on 2016 Aug $16]$. 